\title{
Сорбционные характеристики и диффузионная проницаемость анионообменной мембраны МА-41 в растворах молочной кислоты
}

\author{
(C) 2021 Козадерова О.А., Калинина С.А., \\ Моргачева Е.А., Нифталиев С.И.
}

Воронежский государственный университет инженерных технологий, Воронеж

Поступила в редакцию 23.03.2021 г.

DOI: $10.17308 /$ sorpchrom.2021.21/3465

Работа посвящена изучению закономерностей ионного и молекулярного транспорта в системе «молочная кислота - хлорид натрия - анионообменная мембрана МА-41». Построены кинетические кривые ионообменной сорбции молочной кислоты, показано, что время достижения максимальной рабочей обменной емкости мембраны составляет от 35 до 80 минут в зависимости от концентрации раствора. Получены изотермы обменной сорбции и необменного поглощения молочной кислоты в диапазоне концентраций раствора 0.03-0.15 моль/дм³. Изотерма обменной сорбции описывается уравнением мономолекулярной адсорбции Ленгмюра с высоким коэффициентом корреляции. Величина необменного поглощения молочной кислоты заметно возрастает при концентрации раствора $>0.10$ моль/дм однако, общее количество поглощенной молочной кислоты (в результате обменной и необменной сорбции) остается меньше, чем полная обменная емкость мембраны МА-41. Приведены концентрационные зависимости диффузионной проницаемости мембраны в растворах молочной кислоты, хлорида натрия и смешанном растворе, где молочная кислота и минеральная соль находятся в эквимолярном соотношении. Для молочной кислоты в диапазоне концентраций 0.03-0.30 моль/дм ${ }^{3}$ коэффициент диффузионной проницаемости мембраны МА-41 имеет более высокое значение, чем для хлорида натрия. Причиной ограничения переноса минеральной соли служит Доннановское исключение. Присутствие в растворе молочной кислоты эквивалентного количества хлорида натрия приводит к уменьшению коэффициентов диффузионной проницаемости последней в 2.5-3.2 раза по причине сопряжения потоков. Полученные экспериментальные результаты позволят осуществить обоснованный выбор рабочего диапазона концентраций обрабатываемых растворов для реализации экологически перспективных технологий Доннановского диффузионного диализа в очистке и получении молочной кислоты.

Ключевые слова: молочная кислота, хлорид натрия, анионообменная мембрана, диффузионная проницаемость, сорбция.

\section{Введение}

Одним из вариантов получения молочной кислоты является биохимический способ, основанный на сбраживании молочнокислыми бактериями моно- и дисахаридов, многоатомных спиртов, многоосновных кислот [1, 2]. Для получения молочной кислоты из молочной сыворотки последнюю очищают от белков, за- тем вносят закваску. Через сутки активного брожения $\mathrm{pH}$ сыворотки понижается, что замедляет действие бактерий. Поэтому сыворотку раскисляют (нейтрализуют), например, меловым молоком. Нейтрализованную сыворотку очищают от осадка (белка, солей), в фильтрате остается молочнокислый кальций (около $15 \%$ масс.). Для получения молочной кислоты фильтрат обрабатывают серной кислотой. При этом выделяется нерастворимый сульфат кальция. Биохимический 
Таблица 1. Общие свойства молочной кислоты

Table 1. Main characteristics of lactic acid

\begin{tabular}{|c|c|}
\hline Формула & $\mathrm{H}_{3} \mathrm{C}-\mathrm{CH}(\mathrm{OH})-\mathrm{COOH}$ \\
\hline М, г/моль & 90.08 \\
\hline рК диссоциации & 3.77 \\
\hline Длина, $10^{-10}$ м & 5.27 \\
\hline Объем, см ${ }^{3} /$ моль & 63.49 \\
\hline $\begin{array}{c}\text { pH водных растворов для разных кон- } \\
\text { центраций }\end{array}$ & 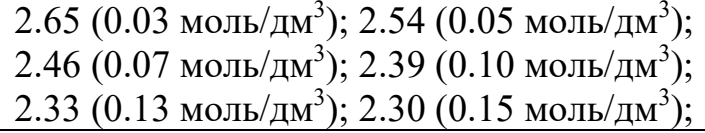 \\
\hline $\begin{array}{c}\text { Коэффициент диффузии лактат-иона в } \\
\text { растворе, } 10^{-9}, \mathrm{~m}^{2} \cdot \mathrm{c}^{-1}\end{array}$ & 1.033 \\
\hline
\end{tabular}

способ получения молочной кислоты, предполагающий нейтрализацию молочной кислоты в процессе её получения не меловым молоком, а раствором гидроксида натрия, с последующей обработкой нейтрализованной сыворотки в электродиализаторе-синтезаторе с биполярными мембранами предложен в работе [3], что позволяет снизить количество отходов при ее производстве. Электромембранная обработка в электродиализаторе-концентраторе с чередующимися катионо- и анионообменными мембранами является также перспективным вариантом для деминерализации молочной сыворотки [4]. Знание основных закономерностей ионного и молекулярного транспорта отдельных компонентов сложной системы может быть полезным как при решении прикладных задач в технологии молочной кислоты (получение целевого продукта, очистка растворов после проведения микробиологического синтеза), так и фундаментальных. В частности, сорбционные характеристики мембраны необходимы для понимания механизма сорбции органических кислот ионообменниками [5], для расчета кинетических параметров ионов органических кислот в ионообменных мембранах [6], важных в моделировании и интерпретации ионного транспорта в электромембранных системах. В связи с этим необходимо осуществлять поэтапное исследование сложной мембранной системы, содержащей водные растворы органических и минеральных веществ.
Цель настоящей работы - изучение сорбционных характеристик и диффузионной проницаемости анионообменной мембраны МА-41, находящейся в контакте с растворами молочной кислоты.

\section{Экспериментальная часть}

В статье рассмотрена сорбция молочной кислоты анионообменной мембраной $\mathrm{MA}-41\left(\mathrm{Cl}^{-}\right.$- ионная форма) из растворов с концентрацией 0.03-0.15 моль/дм ${ }^{3}$ и диффузионная проницаемость МА-41 в растворах молочной кислоты, хлорида натрия, а также в смешанных растворах молочной кислоты и хлорида натрия, где органическая кислота и минеральная соль находятся в эквимолярном соотношении (диапазон концентраций 0.030.5 моль/дм $\left.{ }^{3}\right)$.

Свойства молочной кислоты и ее водных растворов представлены в таблице 1 и на рис. 1 [7-9]. В растворах изучаемых концентраций изначально молочная кислота находится преимущественно в молекулярной форме (доля HLac в этих растворах 0.94-0.97).

Исследуемая мембрана - МА-41 - гетерогенная, серийно выпускаемая Щекиноазот, Россия. Изготавливается на основе анионита AB-17 [10]. Это сильноосновный монофункциональный анионообменник, содержащий, в основном (около $80 \%$ ), четвертичные аммониевые группы (некоторое количество вторичных и третичных аминогрупп появляется в мембране в процессе хранения, эксплуатации и транспортировки). Она построена на основе полистирол-дивинилбензольной 


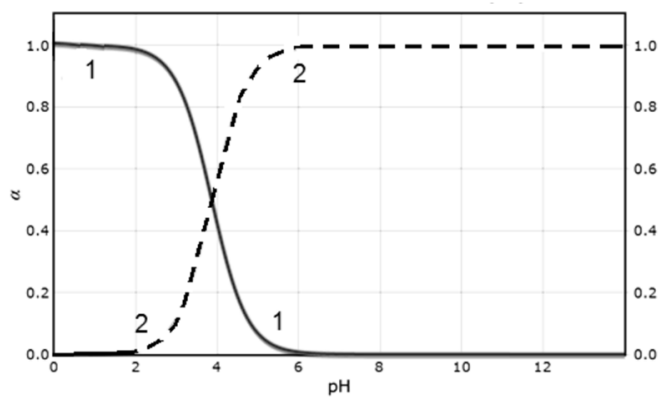

Рис. 1. Распределение кислотно-основных форм молочной кислоты в зависимости от pH раствора: 1 - доля HLac; 2 - доля $\mathrm{Lac}^{-}$

Fig. 1. Distribution of acid-base forms of lactic acid depending on the $\mathrm{pH}$ of the solution: 1 - share of HLac; 2 - share of Lac

матрицы, в качестве инертного связующего содержит полиэтилен. Полная обменная емкость по хлорид-иону равна 2.1 ммоль/г сух. мембраны.

Сорбция молочной кислоты из растворов с $\mathrm{pH} 2.30-2.65$ мембраной $\mathrm{MA}-41{\text { в } \mathrm{Cl}^{-}}^{-}$ -форме может протекать как по ионообменному механизму, так и необменно. В результате ионообменной сорбции $\mathrm{Lac}^{-}$в раствор переходит эквивалентное количество противоионов $\mathrm{Cl}^{-}$из мембраны. В свою очередь, при уменьшении концентрации Lac в в растворе равновесие диссоциации молочной кислоты смещается в сторону образования ионизированных частиц: лактат-анионов, способных к обменному поглощению, и катионов водорода, обеспечивающих подкисление контактирующего с мембраной раствора. В целом при сорбции в контактирующем с мембраной растворе меняется соотношение ионно-молекулярных форм молочной кислоты и идет накопление сильной кислоты. Ионообменную сорбцию изучали на основе анализа кинетических кривых. Получение кинетических кривых сорбции проводили в статических условиях методом ограниченного объема [11]. Навеску мембраны 1.5 г, взятую на аналитических весах, помещали в растворы молочной кислоты с концентрациями $0.03 ; 0.05 ; 0.07 ; 0.10 ; 0.13$ и 0.15 моль/дм ${ }^{3}$. Объем раствора выбирался с таким расчетом, чтобы количество молочной кислоты в контактирующем с мембраной растворе в несколько раз превышало полную обменную емкость мембраны. Пере- мешивание раствора осуществляли магнитной мешалкой, в растворах в течение эксперимента контролировали $\mathrm{pH}$ и $\mathrm{pC} \mathrm{Cl}$ для отслеживания окончания процесса сорбции и расчета количества обменно сорбированной кислоты в зависимости от времени контакта сорбата и сорбента. Для определения необменной сорбции молочной кислоты по окончании процесса проводили потенциометрическое титрование равновесного раствора кислоты раствором щелочи [12].

Измерения диффузионной проницаемости исследуемой ионообменной мембраны $\left(P_{\mathrm{M}}\right)$ проводили в проточной двухкамерной ячейке (рис. 2) с рабочей площадью мембраны $\mathrm{A}=8 \mathrm{~cm}^{2}$ согласно методике [13]. Перед проведением эксперимента мембрану выдерживали в исследуемом растворе не менее 8 часов. Анализируемый раствор (раствор молочной кислоты, или хлорида натрия, или раствор, содержащий молочную кислоту и хлорид натрия в эквимолярном соотношении) с концентрацией $0.03 ; 0.05 ; 1.0$; $1.5 ; 0.3$ или 0.5 моль/дм ${ }^{3}$ поступал в емкость 2. Циркулирующий объем раствора 5.0 дм $^{3}$. В емкость 3 изначально в режиме рецикла поступала вода (объем $\mathrm{V}=0.1$ дм $^{3}$ ). В емкости 3 непрерывно регистрировали электропроводность $(k), \mathrm{pH}, \mathrm{pC} \mathrm{Cl}$, $\mathrm{pC}_{\mathrm{Na}}+$ и температуру. В емкости 2 определяли эти параметры перед началом и после окончания эксперимента. После достижения системой стационарного состояния, при котором тангенс угла наклона 


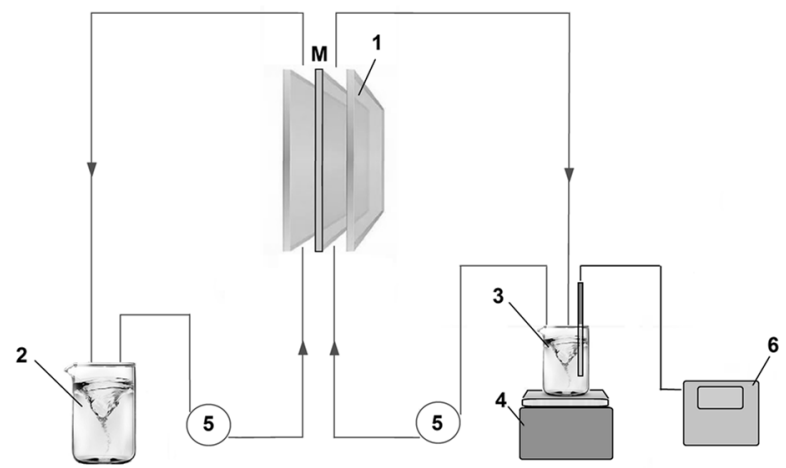

Рис. 2. Схема лабораторной установки для измерения диффузионной проницаемости: 1 - двухкамерная проточная ячейка с мембраной (M); 2, 3 - емкости с раствором соли (кислоты, соли и кислоты) и воды соответственно; 4 - магнитная мешалка; 5 - перистальтические насосы; 6 - измеритель электропроводности (кондуктометр), иономер, pH-метр Fig. 2. Scheme of laboratory unit for measuring diffusion permeability: 1 - two-chamber flow cell with a membrane $(\mathrm{M}) ; 2,3$ - containers with a solution of salt (acids, salts and acids) and water, respectively; 4 - magnetic stirrer; 5 - peristaltic pumps; 6 - electrical conductivity meter

(conductometer), ionomer, $\mathrm{pH}$ meter

зависимости «электропроводность раствора в емкости 3 - время эксперимента $(\tau) »$ становится постоянным, эксперимент прекращали. Полученные для стационарного состояния системы зависимости использовали для нахождения значения $d c_{\mathrm{i}} / d \tau$ по известным экспериментальным данным с применением уравнения:

$$
k=\frac{F^{2}}{R \cdot T} \sum_{i=1}^{n} z_{i}^{2} \cdot D_{i} \cdot c_{i},
$$

где $\mathrm{D}_{\mathrm{i}}, \mathrm{Zi}, \mathrm{c}_{\mathrm{i}}$ - коэффициент диффузии, заряд и концентрация i-го компонента электролита.

Расчет диффузионной проницаемости мембран проводили по формуле:

$$
P_{M}=\frac{V \cdot d}{A \cdot c_{i}^{0}} \cdot \frac{d c_{i}}{d \tau}
$$

где $d$ - толщина мембраны; $c_{\mathrm{i}}^{0}-$ концентрация компонента в отдающей камере.

Кроме величины диффузионной проницаемости был рассчитан фактор разделения $\left(\mathrm{S}_{\mathrm{F}}\right)$ для системы молочная кислота/хлорид натрия:

$$
S_{F}=\frac{c_{\mathrm{MK}}^{\mathrm{KoH}}}{c_{\mathrm{NaCl}}^{\mathrm{KoH}}}: \frac{c_{\mathrm{MK}}^{0}}{c_{\mathrm{NaCl}}^{0}} .
$$

где $\mathrm{c}^{0}$ - концентрация раствора молочной кислоты (МК) или хлорида натрия в отдающей камере; $\mathrm{c}^{\text {кон }}$ - концентрация рас- твора молочной кислоты (МК) или хлорида натрия в принимающей камере после окончания эксперимента.

Для организации функционирования лабораторных установок и анализа растворов применялось следующее оборудование: насос перистальтический трехканальный РP 2В-15; кондуктометр лабораторный SanXin DDS-11C; pH-метр лабораторный $\mathrm{pH}-150$ МИ, иономер лабораторный И-130, магнитная мешалка AMTAST MS-200.

\section{Обсуждение результатов}

Кинетические кривые ионообменной сорбции молочной кислоты мембраной МА-41 из индивидуальных водных растворов с концентрациями $0.05,0.10$ и 0.15 моль/дм ${ }^{3}$ представлены на рис. 3. Форма зависимостей $q-\tau$ имеет вид кривых насыщения. При сорбции $\mathrm{Lac}^{-}-$ионов анионообменной мембраной МА-41 время достижения максимальной рабочей обменной емкости составляет от 35 до 80 минут в зависимости от концентрации раствора. Из кинетических кривых сорбции при максимальном насыщении мембраны построена изотерма обменной сорбции (рис. 4, а). Эта зависимость хорошо описывается уравнением мономолекулярной адсорбции Ленгмюра [14]. На 


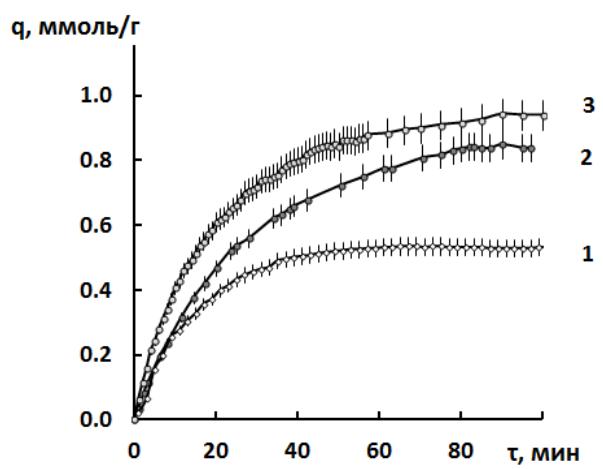

Рис. 3. Кинетические кривые обменной сорбции молочной кислоты из индивидуальных водных растворов с концентрациями 0.05 моль/дм³ $(1) ; 0.10$ моль/дм ${ }^{3}$ (2);

0.15 моль $/$ дм $^{3}$ (3) анионообменной мембраной MA-41 в $\mathrm{Cl}^{-}$ионной форме

Fig. 3. Kinetic curves of exchange sorption of lactic acid from individual aqueous solutions with concentrations of $0.05 \mathrm{~mol} / \mathrm{dm}^{3}(1) ; 0.10 \mathrm{~mol} / \mathrm{dm}^{3}$ (2); $0.15 \mathrm{~mol} / \mathrm{dm}^{3}$ (3) anion-exchange

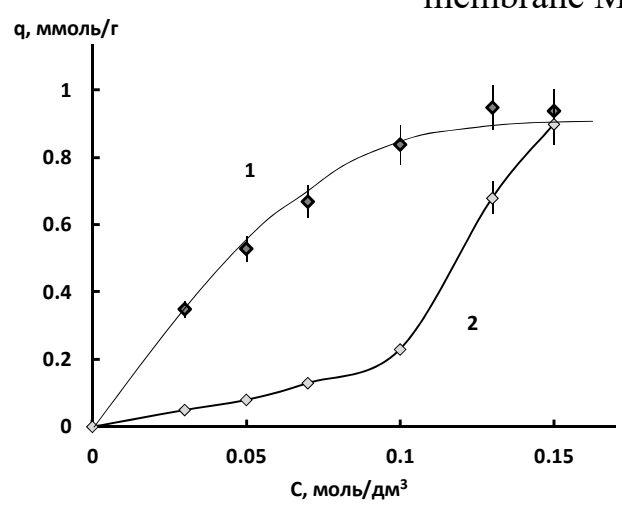

a

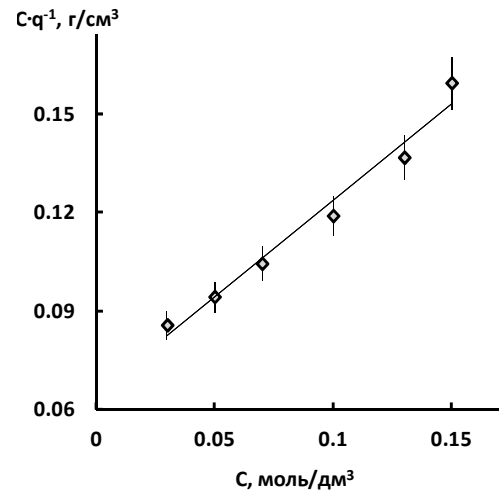

б

Рис. 4. Изотермы ионного обмена (1) и необменного поглощения (2) молочной кислоты мембраной MA-41 ( $\mathrm{Cl}^{-}$- форма) (a); ионообменной сорбции молочной кислоты (б)

Fig. 4. Isotherms of ion exchange (1) and nonexchangeable absorption (2) of lactic acid by the MA-41 ( $\mathrm{Cl}^{-}$- form) (a); ion exchange sorption of lactic acid (b)

рис. 4 (б), приведена данная зависимость в координатах $\mathrm{C} \cdot \mathrm{q}^{-1}-\mathrm{C}$, позволяющих перейти к линейной форме уравнения (коэффициент корреляции $\left.\mathrm{R}^{2}=0.9751\right)$. Кривая 2 (рис. 4 (a), показывает концентрационную зависимость необменного поглощения молочной кислоты. Мы видим, что эта величина заметно возрастает при концентрации раствора молочной кислоты $>$ 0.10 моль/дм ${ }^{3}$. Однако общее количество поглощенной молочной кислоты (в результате обменной и необменной сорбции) остается меньше, чем полная обменная емкость мембраны МА-41. Это отличается от данных, полученных в исследовании [8], посвященном сорбции молочной кислоты гранулированным ионитом AB-16 в $\mathrm{OH}^{-}$ионной форме, где авторы получили для всех исследуемых концентраций раствора молочной кислоты (0.1111-0.0278 моль/дм ${ }^{3}$ ) превышение полной обменной емкости на 20-23 \% за счет необменного поглощения.

Диффузионная проницаемость мембраны в изучаемых растворах показана на рис. 5. Для соли диффузионная проницаемость при низких концентрациях мала, причиной ограничения переноса является Доннановское исключение: матрица мембраны, имеющая одинаковый по знаку заряд с ионами сильного электролита в растворе (в нашем случае с катионами натрия), не дает заряженным частицам проходить через мембрану, наблюдается их электростатическое отталкивание, «исключение» из мембраны. С ростом концентрации раствора хлорида натрия 


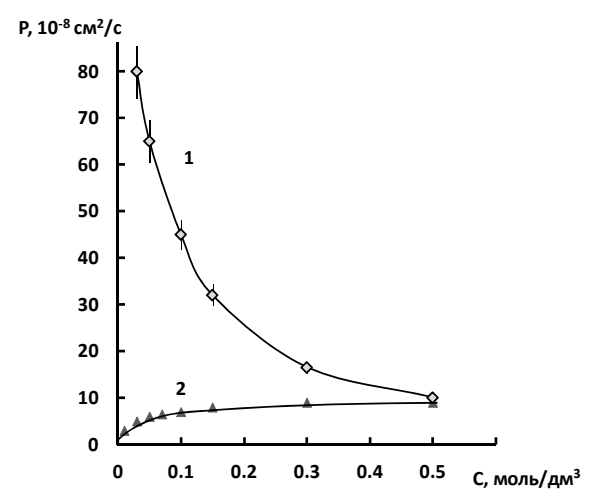

a

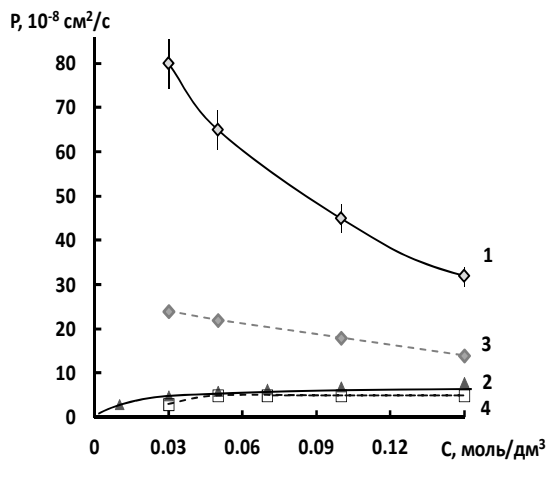

6

Рис. 5. Зависимость коэффициентов диффузионной проницаемости от концентрации растворов: а - при диффузионном переносе молочной кислоты (1) и хлорида натрия (2) из индивидуальных растворов; б - при диффузионном переносе молочной кислоты (1), хлорида натрия (2) из индивидуальных растворов и (3), (4) - молочной кислоты и хлорида натрия соответственно из смешанного раствора с эквимолярным соотношением компонентов

Fig. 5. Dependence of the diffusion permeability coefficients on the concentration of solutions: a - during the diffusion transfer of lactic acid (1) and sodium chloride (2) from individual solutions; $b$ - with diffusion transfer of lactic acid (1), sodium chloride (2) from individual solutions and (3), (4) - lactic acid and sodium chloride, respectively, from a mixed solution with an equimolar ratio of components

доннановское исключение проявляется все в меньшей степени, в связи с этим коэффициент диффузионной проницаемости минеральной соли растет. Полученные результаты согласуются с данными, приведенными в других исследованиях $[15,16]$.

Для молочной кислоты коэффициент диффузионной проницаемости имеет более высокое значение, чем для хлорида натрия, в диапазоне концентраций 0.030.30 моль/дм ${ }^{3}$. Это можно связать с тем, что в растворах таких концентраций молочная кислота существует преимущественно в молекулярной, «не заряженной» форме (HLac, рис. 1, табл. 1), и Доннановское исключение в этом случае заметно не проявляется. Однако, вероятно, механизм переноса молочной кислоты через мембрану является более сложным, чем молекулярная диффузия. В работе [17] показано, что рН внутреннего раствора анионообменной мембраны имеет более высокое значение, чем раствор внешний, контактирующий с мембраной, и возможны случаи, когда $\mathrm{pH}$ внутреннего раствора мембраны увеличивается до значения 6.8, в то время как для внешнего раствора $\mathrm{pH}=3$. Тогда нельзя исключать возможность нахождения молочной кислоты внутри мембраны в ионизированной форме, не смотря на то, что во внешнем растворе она находится преимущественно в молекулярной (рис. 1). Значения величины диффузионной проницаемости молочной кислоты близки к диффузионной проницаемости аминокислоты фенилаланина через гетерогенную катионообменную мембрану МК-40 [16].

Присутствие в растворе молочной кислоты эквивалентного количества хлорида натрия способствует значительному уменьшению коэффициентов диффузионной проницаемости молочной кислоты. На рис. 6 приведен фактор разделения для системы молочная кислота/хлорид натрия, полученный как без учета сопряжения потоков (на основании изучения диффузионного переноса через мембрану кислоты и соли из индивидуальных растворов), так и с учетом сопряжения потоков (по результатам анализа переноса компонентов из смешанного раствора, в котором органическая кислота и 


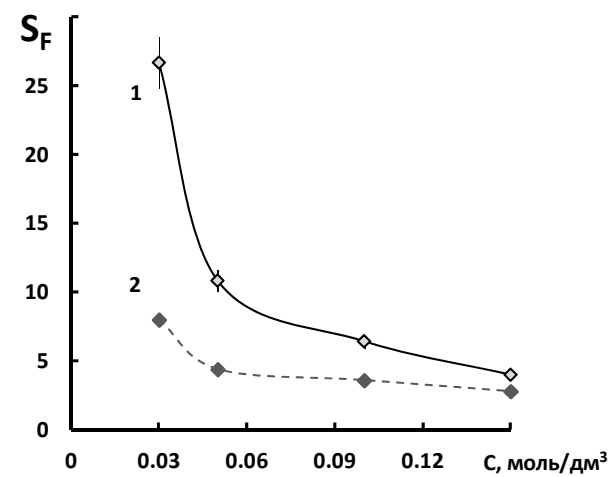

Рис. 6. Зависимость фактора разделения от концентрации растворов молочной кислоты и хлорида натрия: 1 - без учета сопряжения потоков; 2 - при сопряжении потоков молочной кислоты и минеральной соли

Fig. 6. Dependence of the separation factor on the concentration of solutions of lactic acid and sodium chloride: 1 - without taking into account the conjugation of flows; 2 - with the conjugation of flows of lactic acid and mineral salt

минеральная соль находятся в эквимолярном соотношении). Анализ данного рисунка показывает, что наиболее высоких степеней разделения для изучаемой системы можно ожидать для смеси молочная кислота/хлорид натрия в диапазоне концентраций 0.03-0.05 моль/дм³

\section{Заключение}

Исследована система, включающая анионообменную мембрану МА-41 $\left(\mathrm{Cl}^{-}\right.$ форма), растворы молочной кислоты и хлорида натрия. Сорбция молочной кислоты включает как ионный обмен, так и необменное поглощение. Диффузионный

\section{Список литературы}

1. Храмцов А.Г., Павлов В.А., Нестеренко П.Г. Переработка и использование молочной сыворотки: Технологическая тетрадь. М. Росагропромиздат. 1989. $271 \mathrm{c}$.

2. Храмцов А.Г., Нестеренко П.Г. Технология продуктов из молочной сыворотки. М. ДеЛи принт. 2003. 768 с.

3. Шинкарёв С.М., Аксёнов А.В. Патент РФ № 2661792. 2018.

4. Золоторева М.С., Володин Д.Н., Бессонов А.С., Топалов В.К.// Молочная промышленность. 2014. № 3. С. 37-39.

5. Овчаренко Е.О., Васильева В.И., Шапошник В.А., Козадерова О.А. и др. // Сорбиионные и хроматографические прочессы. 2001. T. 1. № 1. C. 84-90. перенос молочной кислоты через мембрану заметно снижается в присутствии минеральной соли. Полученные в статье результаты могут быть полезны при выборе рабочего диапазона концентраций растворов молочной кислоты для оценки возможности применения технологии Доннановского диффузионного диализа на стадии очистки молочной кислоты от минеральных компонентов или технологии конверсии лактата натрия в молочную кислоту в электродиализаторе-синтезаторе.

6. Козадерова О.А., Шапошник В.А. // Электрохимия. 2004. Т. 40. № 7. С. 798-804.

7. Досон Р., Эллиот Д., Эллиот У., Джонс К., Справочник биохимика. М. Мир. 1991. 543 с.

8. Селеменев В. Ф., Ланцузская Е. В., Крисилов А. В., Орос Г. Ю. и др. // Вестник Воронежского государственного университета. Серия: Химия. Биология. Фармация. 2015. № 3 С. 31-36.

9. Волков А.И., Жарский И.М. Большой химический справочник. Минск. Современная школа. 2005. $607 \mathrm{c.}$

10. ООО ИП Щекиноазот. Режим доступа: http://www. azotom.ru/monopolyarnyemembrany (дата обращения: 20.03.2021)

11. Селеменев В.Ф., Славинская Г.В., Хохлов В.Ю. Практикум по ионному обмену. Воронеж. Воронеж. гос. ун-т. 2004. 160 с. 
12. Васильев В.П. Аналитическая химия. В 2 ч. Ч. 2. Физико-химические методы анализа. М. Высшая школа. 1989. 384 с.

13. Никоненко В.В., Ведерникова Е.Е., Письменская Н.Д. Патент РФ № 100275, 2010.

14. Гельфман М.И., Ковалевич О.В., Юстратов В.П. Коллоидная химия. Санкт-Петербург. Лань. 2020. 336 с.

15. Гнусин Н.П., Березина Н.П., Шудренко А.А., Ивина О.П. // Журн. Физ. Химии. 1994. T. 68. № 3. С. 565-570.
16. Vasil'eva V., Goleva E., Pismenskaya N., Kozmai A. et al. // Separation and Purification Technology. 2019. Vol. 210. pp. 48-59. DOI: 10.1016/j.seppur.2018.07.065

17. Pismenskaya N., Laktionov E., Nikonenko V., El Attar A., et al. // Journal of Membrane Science. 2001. Vol. 181. No 2. C. 185-197. DOI: 10.1016/S0376-7388(00)00529-9

\title{
Sorption characteristics and diffusion permeability of the MA-41 anion-exchange membrane in lactic acid solutions
}

\author{
(C) 2021 Kozaderova O.A., Kalinina S.A., Morgacheva E.A., Niftaliev S.I. \\ Voronezh State University of Engineering Technologies, Voronezh
}

\begin{abstract}
The study was devoted to the investigation of the regularities of ionic and molecular transport in the system "lactic acid - sodium chloride - anion exchange membrane MA-41". Kinetic curves of ion-exchange sorption of lactic acid were plotted; it was shown that the time to reach the maximum working exchange capacity of the membrane was from 35 to 80 minutes, depending on the concentration of the solution. Isotherms of exchange sorption and non-exchange absorption of lactic acid in the solution concentration range $0.03-0.15$ $\mathrm{mol} / \mathrm{dm}^{3}$ were obtained. The exchange sorption isotherm is described by the Langmuir monomolecular adsorption equation with a high correlation coefficient. The value of non-exchange absorption of lactic acid noticeably increased at a solution concentration $>0.10 \mathrm{~mol} / \mathrm{dm}^{3}$, however, the total amount of absorbed lactic acid (as a result of exchange and non-exchange sorption) remained lower than the total exchange capacity of the MA-41 membrane. Concentration dependences of membrane diffusion permeability in solutions of lactic acid, sodium chloride and mixed solution, where lactic acid and mineral salt are in equimolar ratio, are shown. For lactic acid in the concentration range $0.03 \mathrm{~mol} / \mathrm{dm}^{3}-0.30 \mathrm{~mol} / \mathrm{dm}^{3}$ diffusion permeability coefficient of MA-41 membrane had a higher value than for sodium chloride. The reason for the limitation of the mineral salt transport is the Donnan exception. The presence of an equivalent amount of sodium chloride in a solution of lactic acid led to a decrease in the diffusion permeability coefficients of lactic acid by $2.5-3.2$ times due to the conjugation of flows. The obtained experimental results will allow making a reasonable choice of the working range of concentrations of the treated solutions for the implementation of ecologically promising technologies of Donnan diffusion dialysis in the purification and production of lactic acid.
\end{abstract}

Keywords: lactic acid, sodium chloride, anion exchange membrane, diffusion permeability, sorption

\section{References}

1. Hramcov A.G., Pavlov V.A., Nesterenko P.G. Pererabotka i ispol'zovanie molochnoj syvorotki: Tehnologicheskaja tetrad', M., Rosagropromizdat, 1989, $271 \mathrm{p}$.

2. Hramcov A.G., Nesterenko P.G. Tehnologija produktov iz molochnoj syvorotki, M., DeLi print, 2003, 768 p.

3. Shinkarjov S.M., Aksjonov A.V. Patent RF No 2661792, 2018.

4. Zolotareva M.S., Volodin D.N., Bessonov A.S., Topalov V.K., Molochnaja promyshlennost', 2014, No 3, pp. 37-39.
5. Ovcharenko E.O., Vasil'eva V.I., Shaposhnik V.A., Kozaderova O.A. et al., Sorbtsionnye $i$ khromatograficheskie protsessy, 2001, Vol. 1, No 1, pp. 84-90.

6. Kozaderova O.A., Shaposhnik V.A., Russian Journal of Electrochemistry, 2004, Vol. 40, No 7, pp. 698-703.

7. Doson R., Jelliot D., Jelliot U., Dzhons K., Spravochnik biohimika, M., Mir, 1991, 543 p.

8. Selemenev V.F., Lantsuzskaya E.V., Krisilov A.V., Oros G.Yu. et al., Vestnik Voronezhskogo gosudarstvennogo universiteta. 
Serija: Himija. Biologija. Farmacija, 2015, No 3, pp. 31-36.

9. Volkov A.I., Zharskij I.M. Bol'shoj himicheskij spravochnik, Minsk, Sovremennaja shkola, 2005, $607 \mathrm{p}$.

10. OOO IP Shhekinoazot. Rezhim dostupa: http://www. azotom.ru/monopolyarnye-membrany (data obrashhenija: 20.03.2021)

11. Selemenev V.F., Slavinskaja G.V., Hohlov V.Ju., Praktikum po ionnomu obmenu. Voronezh, Voronezh. gos. un-t, 2004, 160 p.

12. Vasil'ev V.P. Analiticheskaja himija, V 2 ch. Ch. 2. Fiziko-himicheskie metody analiza. M., Vysshaja shkola, 1989, 384 p.

13. Nikonenko V.V., Vedernikova E.E., Pismenskaya N.D. Patent RF № 100275, 2010.

Козадерова Ольга Анатольевна - доцент кафедры неорганической химии и химической технологии, д.Х.н, Воронежский государственный университет инженерных технологий, Воронеж

Калинина Стефания Алексеевна - студент Воронежского государственного университета инженерных технологий, Воронеж

Моргачева Елена Андреевна - студент Воронежского государственного университета инженерных технологий, Воронеж

Нифталиев Сабухи Илич-оглы - зав. кафедрой неорганической химии и химической технологии, д.Х.н., Воронежский государственный университет инженерных технологий, Воронеж
14. Gel'fman M.I., Kovalevich O.V., Justratov V.P. Kolloidnaja himija, Sankt-Peterburg, Lan', 2020, $336 \mathrm{p}$.

15. Gnusin N.P., Berezina N.P., Shudrenko A.A., Ivina O.P., Russian Journal of Physical Chemistry A, 1994, Vol. 68, No 3, pp. 506-511.

16. Vasil'eva V., Goleva E., Pismenskaya N., Kozmai A. et al., Separation and Purification Technology, 2019, Vol. 210, pp. 48-59. DOI: 10.1016/j.seppur.2018.07.065

17. Pismenskaya N., Laktionov E., Nikonenko V., El Attar A. et al., Journal of Membrane Science, 2001, Vol. 181, No 2, pp. 185-197. DOI: $10.1016 / \mathrm{S} 0376-7388(00) 00529-9$

Kozaderova Olga A. - associate prof., Dr. habil. (chemistry), department of inorganic chemistry and chemical technology, Voronezh State University of Engineering Technologies, Voronezh, e-mail: kozaderova-olga@mail.ru

Kalinina Stefanya A. - Student of Voronezh State University of Engineering Technologies, Voronezh, e-mail: stefanya-kalinina@yandex.ru

Morgacheva Elena A. - Student of Voronezh State University of Engineering Technologies, Voronezh, e-mail: lena_morgacheva@mail.ru

Niftaliev Sabukhi I. - head of Department Dr. habil. (chemistry), department of inorganic chemistry and chemical technology, Voronezh State University of Engineering Technologies, Voronezh, email: sabukhi@gmail.com 